NBSIR 83-2784-2

\title{
The Automated Office - An Environment for Productive Work, or an Information
}

\section{Factory?: \\ Executive Summary}

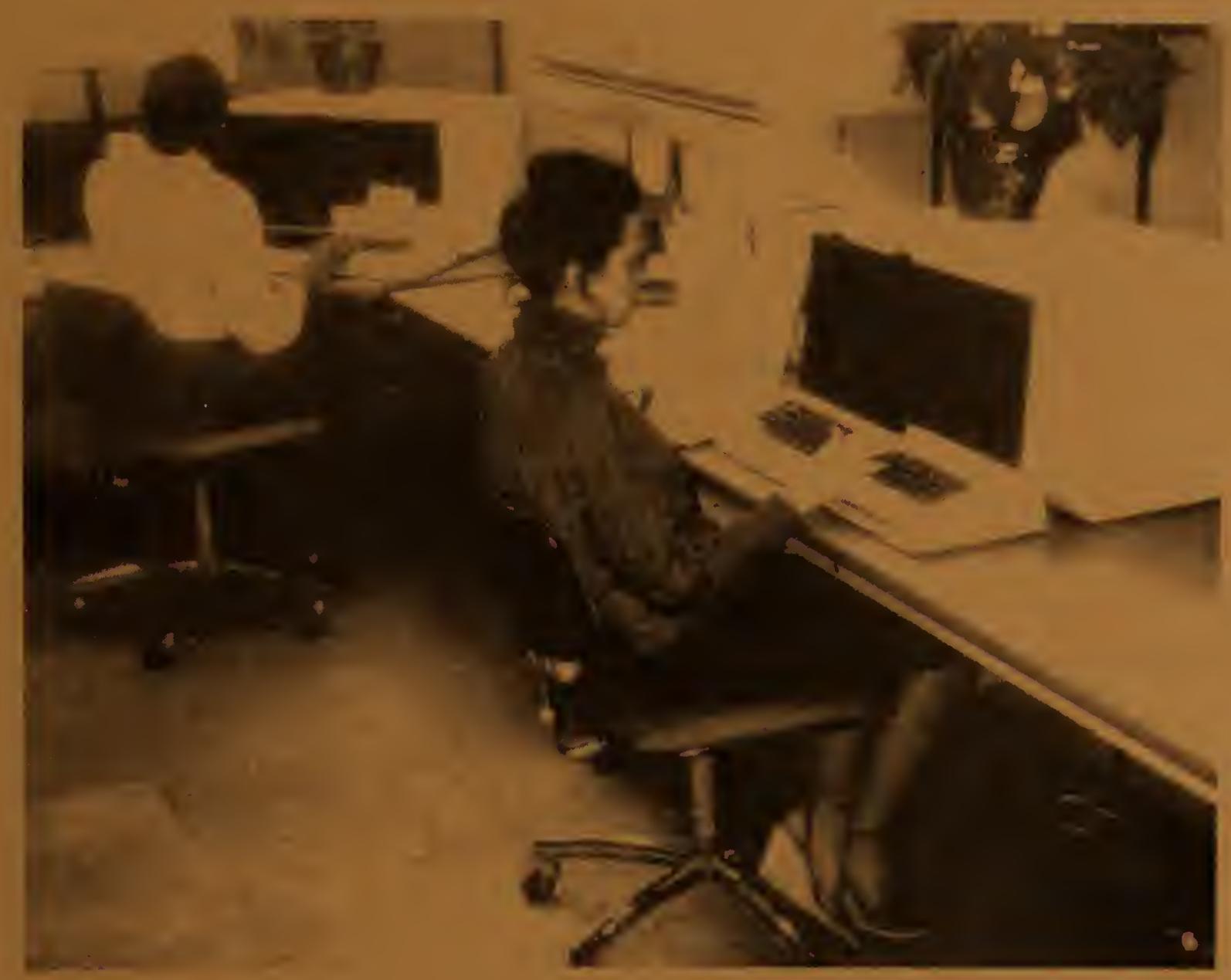

December 1983

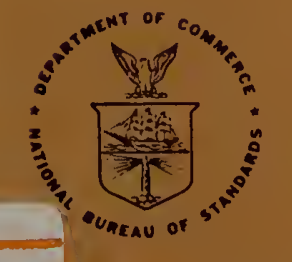

Inter for Building Technology ational Engineering Laboratory ational Bureau of Standards

100 1.456

33-2734-2 a shington, DC 20234 1983

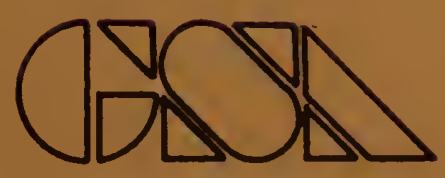

Public Buildings Service General Services Administration Washington, DC 20405 

NBSIR 83-2784-2

THE AUTOMATED OFFICE: AN ENVIRONMENT FOR PRODUCTIVE WORK, OR AN INFORMATION FACTORY?:

EXECUTIVE SUMMARY

Arthur Rubin

U.S. DEPARTMENT OF COMMERCE

National Bureau of Standards

National Engineering Laboratory

Center for Building Technology

Washington, DC 20234

December 1983

Prepared for:

Public Buildings Service

General Services Administration

Washington, DC 20405

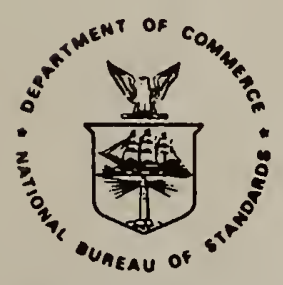

U.S. DEPARTMENT OF COMMERCE, Malcolm Baldrige, Secretary NATIONAL BUREAU OF STANDARDS, Ernest Ambler, Director 



\section{ABSTRACT}

This report summarizes research that produced findings and recommendations on factors which influence automated office design. The subjects include: office design, office information systems, organizational factors, ergonomics, technology, and communications.

Advances in technology, coupled with the explosive growth of office-based work have resulted in the automation of many offices. To date, technology has provided the major impetus for automation, with mixed results. Systems frequently do not meet the needs of the end-user because of the lack of appropriate planning. Design issues are particularly neglected during planning, resulting in problems with the visual, thermal, and acoustic environment in many offices. These effects are particularly detrimental since many office automation, management, and design experts agree that the quality of the environment is especially important in the electronic office - to offset the impersonality of many office tasks, and changes in work procedures resulting in limited social interaction with colleagues. These issues are summarized as they relate to the development of design guidelines and criteria for automated offices. The research was sponsored by the Public Building Service of the General Services Administration under GSA/NBS Interagency Agreement No. PBS-80-1. The state-ofthe-art report that serves as the basis of this executive summary is available as a separate publication, NBSIR 83-2784-1, "The Automated Office - An Environment For Productive Work, Or An Information Factory?: A Report On The State-of-the-Art."

Key Words: acoustic and visual privacy; design criteria; ergonomics; lighting; noise; office automation; office design criteria; quality-of-life; space planning; VDT's (video display terminal); workstation requirements. 


\section{ACKNOWLEDGMENTS}

I would like first to express my particular appreciation to Erma Striner of the Public Buildings Service of the General Services Administration for her assistance, guidance, and unfailing enthusiasm for the work reported here. John Murray of the General Services Administration provided technical assistance on the project, and contributed to the success of several of the site visits performed as part of this study. Belinda Collins, Noel Raufaste, and Ted Hattenberg served as technical readers for this paper, and their sugggestions for revising early drafts are gratefully acknowledged.

Finally, I would like to acknowledge the work performed by Keith Mackley in producing the illustrations in this document, and the typing support provided by CBT's Word Processing Center. 
1. BACKGROUND . ....................................... 1

2. SCOPE, METHODS, AND GOALS OF STUDY $\ldots \ldots \ldots \ldots \ldots \ldots \ldots \ldots \ldots \ldots \ldots \ldots \ldots \ldots . \ldots \ldots$

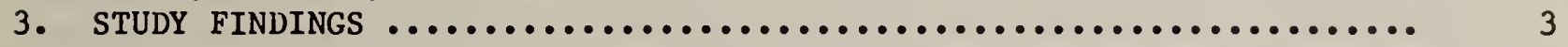

3.1 OVERVIEW .......................................

3.2 EXPERIENCES WITH OFFICE AUTOMATION $\ldots \ldots \ldots \ldots \ldots \ldots \ldots \ldots \ldots \ldots \ldots \ldots . \ldots \ldots$

3.3 TECHNOLOGICAL ISSUES $\ldots \ldots \ldots \ldots \ldots \ldots \ldots \ldots \ldots \ldots \ldots \ldots \ldots \ldots \ldots \ldots \ldots \ldots \ldots . \ldots \ldots$

3.4 ORGANIZATIONAL AND MANAGEMENT ISSUES $\ldots \ldots \ldots \ldots \ldots \ldots \ldots \ldots \ldots \ldots \ldots \ldots$

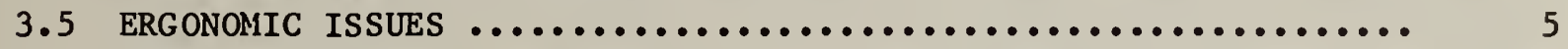

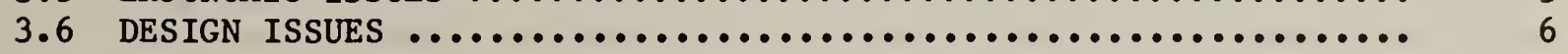

3.6.1 Architectural Programming ....................... 6

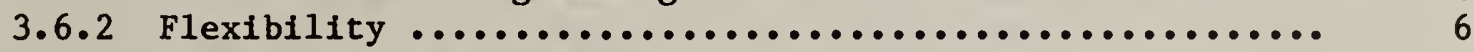

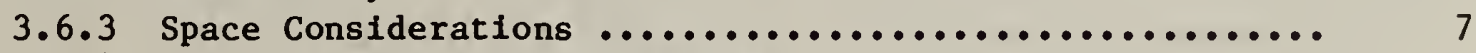

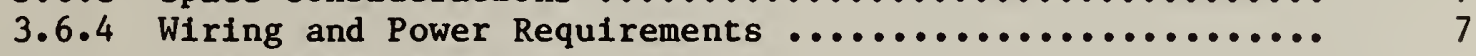

3.6 .5 Local Area Networks ............................ 8

3.6 .6 Specialized Spaces ............................. 8

3.6 .7 Workstation Consideration ....................... 9

3.6 .8 Lighting Issues ............................. 10

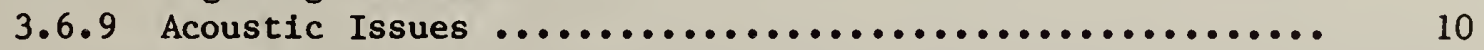

4. CONCLUSIONS AND RECOMMENDATIONS $\ldots \ldots \ldots \ldots \ldots \ldots \ldots \ldots \ldots \ldots \ldots \ldots \ldots \ldots \ldots \ldots . \ldots \ldots$

5. BIBLIOGRAPHY ....................................... 15 



\section{BACKGROUND}

At present, the Federal government owns or operates more than 10,000 buildings throughout the United States. A significant portion of this occupied space is devoted to office-based activities. In this respect the experience of the Federal government parallels that of the private sector. A recent study by the American Productivity Center $1 /$ indicates that about 53 percent of the adult workforce in this country is engaged in white-collar work, accounting for 70 percent of the total payroll of industry. (In 1979, the payroll figure exceeded $\$ 600$ billion.) At the same time that the country is evolving into an information economy, the productivity of office workers showed a growth rate of only 0.02 percent per year for the period 1979 to 1981. As a means of increasing office productivity, many new products and systems directed toward automating office functions have been introduced into federal and private sector buildings. Initially, the office automation activities were directed toward improving the efficiency of routine clerical tasks, but the emphasis now is on the jobs performed by knowledge workers - the managers and professionals - who are considered to be the "key" to increased office productivity, and more importantly, organizational effectiveness. The automation of clerical, professional and management activities has changed the nature of many of these jobs, and has already influended the design of offices. However, the potential design implications of office automation are not well understood since they have not been the subject of systematic investigation.

In order to effectively house the automated office, the Public Building Service of the General Services Administration (PBS/GSA) must be capable of specifying environmental, spatial, and other criteria to support the administrative and operational activities performed in federal buildings. The criteria now available for this purpose are responsive to the traditional office, which is dominated by "paper work." The advent of office automation has changed the office environment in many ways, and design criteria and guidelines are required which are responsive to these changes. The long-term objective of the work reported here is the development of such criteria and guidelines. A necessary prerequisite for developing the information required for criteria and guidelines is the identification of the characteristics of the physical environment which merit particular attention for the automated office. However, if design criteria and guidelines are to achieve their maximum usefulness, they must not be limited to the physical attributes of buildings and technology, but must be responsive to the particular needs of an organization and its staff. In the case of the automated office, a major consideration is the desirability of taking advantage of technological advances as a means of increasing productivity, while at the same time responding creatively to its most important asset - the organizational workforce. Phase 1 of this project considers all of these issues, and the detailed findings appear in a state-of-the-art report (NBSIR-83-2784-1).

1/ "White Collar Productivity: The National Challenge," The Productivity Center, Houston, Texas, 1983. 


\section{SCOPE, METHODS, AND GOALS OF STUDY}

The major objective of the study conducted by the National Bureau of Standards was to obtain information which could be used in the formulation of design guidelines and criteria for federal offices. We were particularly sensitive to the issue that if criteria are to be valid, they should be based upon "hard information" to the greatest extent possible, not merely opinion. That is, design recommendations should be supported by a body of information (preferably based on research findings), which explain the rationale for them.

Several approaches were used to determine the state-of-the-art of office automation and design. One approach was the review and analysis of several hundred published articles from technical and design publications, and dozens of books. This process entailed the examination of data bases covering several disciplinary areas, since the relevant information is widely scattered. Among the topics covered were: Architecture, Interior Design, Ergonomics, Management and Organization, Office Systems, Telecommunications, Electrical Systems, Lighting, Acoustics, Information Management, and Environmental Psychology.

A "case study" approach was used to gain detailed information concerning the introduction of automation in Federal and private organizations. The U.S. Navy Facilities Command and the office Systems Section of the Department of the Army were visited, and interviews conducted concerning office automation activities. Three site visits were also conducted at organizations which had automated office activities (The Boeing Corp., The Sheraton Corp., and Citicorp). The purposes of these visits were: 1) to gain insights about the processes used to plan and implement office automation systems, and 2) to obtain information concerning what did (and didn't) work, and why. Extensive in-depth interviews were conducted with various users and planners at each location.

Personal and telephone interviews were conducted with design and office automation professionals concerning their opinions about present design implications of office automation, the adequacy of available information, and their forecasts about future design requirements. Since office information is a rapidly developing field, much of the published information is not current. Several conferences devoted to this topic were attended to ensure that the state-of-the-art report, and the present one, reflect the latest findings and opinions. (Design issues are not general agenda items at such conferences, and are rarely mentioned at the meetings.)

Also, 60 architectural and 10 interior design firms were sent letters of inquiry concerning how their design practices have changed as a result of office automation, and their forecasts about future implications. 


\section{STUDY FINDINGS}

\subsection{OVERVIEW}

Office design is an important factor in determining whether office automation succeeds or fails to increase organizational productivity and effectiveness. Research findings suggest that the employees of automated offices are more likely to place a high priority on the quality of the workplace than their counterparts working in traditional offices. Several factors support this conclusion:

- The nature of the office workforce is changing. More and more knowledge workers are engaged in automated office activities. Their experiences and expectations concerning the quality of the office environment differ significantly from those of clerical personnel.

- The nature of the work to be performed is very demanding. Planning and creative thinking are important attributes of many activities; both proceses are very susceptible to disruption by environmental or other intrusions. Many knowledge workers are untrained in the use of video display terminals (VDT's) and are therefore sometimes faced with the multiple task of mastering the intricacies of programming, while performing their job functions.

- As occasional respite is needed from the technologically-based environment during the working day. Settings are needed for informal social interactions among colleagues whose work consists of manipulating information by means of VDT's.

Designers have an important contribution to make in furthering organizational and working group cohesiveness. The advent of the microcomputer based workstation has enabled many jobs to be performed autonomously, thereby isolating the individual worker from the group to which he is assigned, and from the organization as a whole.

\subsection{EXPERIENCES WITH OFFICE AUTOMATION}

The automation of office functions has been looked upon as the solution to the productivity problem, but many experts now consider this viewpoint to be an oversimplified one which has led to several problems. The first automated systems introduced into offices were word processors, designed to increase the efficiency of typing. The results of this experience were mixed. One problem encountered was the approach taken in designing such systems - derived from the factory assembly-line system. Routine work tasks were analyzed, simplified, and standardized as a means of increasing efficiency (defined as reducing the unit cost of producing a given product). This approach has resulted in frequent complaints by office workers that they were no longer "in charge" of their jobs; the machines were said to determine what to do, and how to do it. Another major objection cited was the impersonal nature of the job; there was little personal interaction between the individuals engaged in a common activity. 
Another factor which compromises the quality of the office environment is automation that was introduced in open-office settings with insufficient attention given to the requirements for freedom from distraction from noise or other factors. Furthermore, when VDT's are employed as word processors, they are often placed on traditional desks as substitutes for typewriters, without sufficient attention to the differences between the two devices from the standpoint of the operator, or the environmental systems (e.g., lighting) required to support this activity.

The proper introduction of automation into an organization is an important determinant of 1 ts ultimate success in the view of most office automation experts. Yet decisions about automation are typically ad hoc in nature, based upon the advertised technical capabilities of devices and systems. This hardware-driven approach to automation has frequently resulted in the purchase of systems that are not responsive to the needs of the organizations which acquired them. Detailed planning of organizational requirements, including involvement of the systems end-users, is considered to be the essential prerequisite to automating office activities. A necessary component of this planning process is a consideration of the building design implications of automation. Yet, even organizations which engage in extensive planning activities often neglect this essential factor.

\subsection{TECHNOLOGICAL ISSUES}

Technological advances in telecommunication, computers and office information systems are changing the face of the office. At the macro level of design, systems are now available which can be pre-wired into new buildings to accommodate operational, service, energy conservation, fire safety, and other systems. At the micro level, the workstation is becoming the focal point of the office, equipped with separate data bases structured for use by the individual and linked with other workstations and peripheral equipment, thereby increasing its power and flexibility. The informational resources available at an individual workstation today are equivalent to that available only to large organizations not many years ago.

New devices and systems are routinely introduced into office designed to accommodate traditional paper-based activities. Many of these systems are noisy (e.g., printers, optical character recognition devices), and produce heat which must be properly dissipated. Questionnaire surveys of office workers indicate that environmental quality has often been compromised by the introduction of this equipment because of inadequate consideration of the design consequences of such changes. $2 /$ The fact that automation often occurs incrementally in small steps contributes to the design problem; changes are so gradual that there is little anticipation of the final result, and its consequences.

2/ Zuboff, S., "Psychological and Organizational Implications of ComputerMediated Work," CISR 非1, Cambridge, Mass., June 1981 . 
Paper is being supplanted by electronic and microfiche-based systems as the primary information medium, and office design will have to accommodate the needs of workers processing information in all of these forms at a single workstation, for the indefinite future. Technological advances are being made so rapidly that there is an overriding need for design flexibility to accommodate changes as they occur.

\subsection{ORGANIZATIONAL AND MANAGEMENT ISSUES}

The overall appearance and layout of the office is significantly influenced by the style of organizational management. Organizations differ considerably from one another in this and other ways, and the designer has an important contribution to make in fostering the distinctive qualities of a given organization. An important design consideration concerns the proper balance between diversity and uniformity within an organizational entity, among operating units, and for individuals. A centralized management approach frequently results in considerable uniformity of environment for people occupying similar positions in the organizational hierarchy. Both are centralized and decentralized approaches and are characterized by hierarchical differences with respect to the work environments, but the decentralized approach permits a range of choices within each level of the organizational structure. These choices are sometimes at the level of the working group, and in other instances they extend to the individual worker.

The decentralized approach is gaining considerable acceptance by designers and management experts today, especially with respect to the automated office. The "information explosion", coupled with the complexity of many of the organizational decisions that must be made has fostered the team approach to decision making. Knowledge workers are employed to participate in these activities, and are accustomed to work in this manner when participating in meetings. This experience has carried over into workspace design. Research findings indicate that when end-users are involved in the automation decision process that there is a greater degree of acceptance of such systems. 3

\subsection{ERGONOMIC ISSUES}

Design criteria and guidelines are ultimately concerned with meeting the requirements of the individual office worker. Ergonomics deals with the many factors that are likely to influence these requirements - technological, environmental, design, social and psychological. In the automated office the immediate work-environment of the individual is the workstation, its furnishings and surrounds. The design of these spaces is especially important because of the sensitivity of workstation to changes in technology; many of these advances are directed toward upgrading the power and versatility of the workstation. Recent studies have indicated that the ability to personalize this work area, and have some degree of control of the environment, are important components of job

3/ Uhlig, R., Faber, D., and Bair, J., The Office of the Future, North Holland Pub. Co., New York, N.Y. 1979. 
satisfaction, and ultimately of productivity. The inappropriateness of traditional surrounds and furnishings for VDT-based work has been cited as a major source of dissatisfaction in other surveys of office workers.

\subsection{DESIGN ISSUES}

The findings of this study revealed that little "hard" information exists about the design implications of office automation. Apparently the automated office is too recent a development to have received appropriate attention by the research and design communities. The studies that have been performed have focused on organizational, ergonomics, and technological issues. However, these same investigations have pointed to the importance of design considerations as one of the interdependent factors which are critical to the successful implementation of office automation. 4

In the absence of definitive information for formulating design criteria, the design community must still respond to the needs of the automated office, and it has done so by formulating a range of design practices to cope with specific requirements. These practices often differ from firm to firm, and have not undergone rigorous testing; they therefore do not constitute design recommendations by the National Bureau of Standards. Instead, they represent the informed judgments of design and other office automation professionals. This information should therefore be considered a starting point for developing tentative design guidelines for office automation -- the product of the follow-on phase of the present effort.

The following material is a summary of the responses of design firms to an informational inquiry, and of recommendations which appear in the published 1iterature.

\subsubsection{Architectural Programming}

A major reason given for the limited success of many office automation systems is the inadequacy of planning which preceded implementation. A detailed architectural program is needed to identify potential problem areas and devise appropriate solutions.

\subsubsection{Flexibility}

Technological changes occur so frequently in the office automation area that it is impossible to forecast the design implications with any accuracy. Office design must therefore accommodate a large range of design possibilities despite considerable uncertainty about the nature and timing of technological changes. Among the design issues that merit consideration are:

4/ Yates, R., "Human Factors Aspects of the Electronic Office "In The Electronic Office, IERE Conf. Proc. 非5, London, England, 1980. 
- Localized cooling to accommodate heat loads from electrical equipment.

- Electrical distribution systems to facilitate the introduction of new systems and changes in the location of existing ones.

- Lighting systems to permit individual control when tasks require different lighting, e.g•, VDT, microfiche, or paper-based tasks.

- Communications to accommodate new requirements for internal and external contacts - personal and data bases.

- Workstation design to accommodate a range of tasks and individual requirements.

- Window shades and blinds to permit control of natural light.

- Standardization of components for workstations - work surfaces, panels.

- Changes in space use - rearrangements of organizational units and/or individual workstations to respond to technological and organizational changes.

\subsubsection{Space Considerations}

While space requirements for automated offices have received considerable attention, it is unclear how these requirements differ from those of the traditional office. For example, the phasing out of paper files will reduce the storage requirements in the long term, but for the time being there will be a need for paper, microcfiche and electronic information storage. The following design issues were noted by the design professionals as meriting consideration:

- Expansion space in the building core for installing additional risers for communications and power distribution.

- Additional built-in floor/ceiling and/or wall conduits for future wiring.

- Floors with computer facilities should be higher than other spaces to accommodate wiring.

As the individual workstation concept gains acceptance and is provided with increasing capabilities (and devices), it is likely to require more space than the system which it replaced.

\subsubsection{Wiring and Power Requirements}

Wiring and power management was cited by several design firms as being the most important planning consideration, and the most difficult and expensive one to accommodate. Equipment types, densities, and locations, are all subject to future change, so these systems must be designed to move and be adaptable. Several factors were noted as being of particular importance: 
- An uninterruptable backup power supply is necessary to ensure the continued operation of some critical systems. Such systems typically consist of a battery pack and a spare generator.

- Additional capacity is needed to the main and distribution panels and bus risers to accommodate new equipment requirements.

- Power panels are needed for station-to-station distribution systems.

- Dedicated circuits are needed for certain equipment and systems to ensure their security.

- A favored power distribution system by many design firms was a flat-wire system installed beneath carpet tiles. This was used for power distribution to individual workstations.

\subsubsection{Local Area Networks}

Local area communication networks are being used in offices with increasing frequency and many experts forecast that they will be present in most future automated offices. The network should be able to operate under the typical environmental conditions of the buildings in which it is located, with normal exposure to dust, humidity and temperature changes. Specifications for network performance should include the amount of dedicated cooling required for proper operation, and limits for noise and heat generation to ensure that overall environmental quality is not compromised. The equipment may be required to operate within given electrical constraints, e.g., power, voltage, phase and/or frequency. Specific space requirements for these networks include:

o Room for interconnection units co-located with support units.

- Wall and floor space sufficient to accommodate taps/transcelvers.

- Areas within or outside of walls, ceilings and floors for cabling and repeaters/amplifiers.

- Dedicated rooms or floor space for network control units placed centrally or distributed appropriately.

\subsubsection{Specialized Spaces}

The future office will have to accommodate functions that are not found in traditional offices, and specialized requirements are of ten needed for this purpose. Some spaces are needed to accommodate new capabilities, while others are suggested as organizational responses to the changing office environment. Among the specialized spaces noted are:

- Training rooms with advanced audio-visual capabilities, to be used to continually upgrade the skills of the office staff and ensure adequate preparation before implementing job-design changes. 
- Small and large conference rooms to accommodate formal and informal meetings, and as a place away from the high-technology setting.

- Storage areas to accommodate modular workspace components and replacements equipment.

- Specialized rooms for backup power systems and advanced telecommunications equipments.

- Clustering of equipment with specialized environmental requirements - e.g., copying and printing equipment which produce noise should be isolated from the general workfloor; facilitate cooling by zoning with specialized HVAC control.

- Greater use of atriums, with spaces integrated with the building - to facilitate informal communication and provide a "change of scene."

- Rooms to serve as equipment staging, assembly, and maintenance areas.

\subsubsection{Teleconference Rooms}

The capability now exists to conduct many meetings by teleconferencing and organizations are likely to use this mode of operation more frequently in the future as a means of lowering travel time and the expenses that accompany field trips. The design of spaces to accommodate this function is quite demanding. Among the attributes for such rooms that have been cited as being of special importance are:

- The location is an important consideration; when placed in the "executive suite," many potential users are reluctant to use it.

- The support equipment (facsimile devices, input and ouput sytems) often generates considerable noise and heat. One solution has been to locate this equipment in adjacent rooms which are acoustically isolated and have specialized air conditioning systems.

- Lighting and color selections are of critical importance because of the requirements of televised presentations. Rooms surfaces should be nonreflective, and the colors of carpets and furniture should be neutral.

\subsubsection{Workstation Considerations}

A study by the National Academy of Science ${ }^{5}$ cited the design of the workstation and job features, as being of essential importance in VDT-based work. It especially pointed to the need to accommodate for differences among individual workers with respect to their physical attributes and their preferences.

5/ Video Display, Work and Vision, National Academy Press, Washington, D.C., 1980. 
Among the findings in this investigation and others concerned with this issue are the following:

- The individual should have some "say" in the design and selection of his/her furnishings and equipment, and an opportunity to personalize the workspace.

- Special, separate devices are recommended for adjusting the height of work surfaces, keyboard level, source documents, and terminal screens.

- Chairs with high backrests and adjustable inclinations are recommended.

- Forearm/hands supports should be available for keyboard work, and keyboards should be movable.

\subsubsection{Lighting Issues}

Lighting has been a major source of concern by office workers performing VDTbased activities. A major challenge for lighting designers has been the need to accommodate activities that require VDT, paper and microfiche reading in the course of a single task. The particular problem area noted in most surveys however, is that of glare, which reduces task visibility in VDT work. Several recommendations have been made to reduce glare:

- Drapes, shades, and/or blinds over windows should be closed, especially during direct sunlight conditions.

- Terminals should be properly positioned with respect to windows and overhead lighting; large bright areas should not be reflected on the VDT screen.

- Direct lighting fixtures may need to be recessed; and baffles used to prevent the light fixture from acting as a glare source.

- Walls and other surfaces should have reflectance values of less than 50 percent.

- Desks and other work surfaces should have matte finishes and medium tone colors; black or white surfaces should be avoided.

- Screen holds and/or anti-glare filters should be considered as methods of reducing glare on the VDT screen.

\subsubsection{Acoustic Issues}

Surveys of office workers have identified noise as one of the major problem areas in the automated office. 6 Auditory and visual privacy have also been

6/ Marans, R. and Spreckelmeyer, K., "Evaluating Open and Conventional office Design," Environment and Behavior, Vol. 14, No. 3, May 1982. 
prominently mentioned by workers, especially those occupying open-space offices. Among the suggestions made to offset some of these acoustical problems are:

o The separation of noisy equipment from the general work floor.

- Surface treatment of space with sound absorbing materials such as fiberglass insulation and cloth covered panels.

- Placement of acoustical barriers to reduce noise transmission from one space to adjoining areas.

- Avoidance of sound transmission paths between spaces to protect auditory privacy and minimize noise intrusions.

- Use of vibration damping techniques to prevent material from resonating to a primary source, e.g., an acoustical barrier between a printer and a tabletop. 


\section{CONCLUSIONS AND RECOMMENDATIONS}

The preceding findings indicate that a body of useful information is available to formulate interim guidelines for the design of Federal automated offices. However, "hard" data to establish design criteria for automated offices do not exist, and should be developed if the automated office is to achieve its potential for increasing organizational productivity and effectiveness.

Interim guidelines should be in the form of design implications, considerations, and possible approaches; not a series of detailed recommendations. This approach will provide state-of-the-art of design practices, while avoiding the design constraints which are not supportable by empirical and/or scientific findings. The guidelines should be used as a living document, upgraded periodically as better information becomes available. The needed information covers a range of topics. Some of them follow:

- Considerable experience has been gained by the federal government and the private sector with office automation. These experiences should be evaluated, with a view toward upgrading the interim criteria.

- In recent years office design has followed a trend to open-space planning, with automated offices are being designed using the same general procedures. Yet, surveys of office workers have indicated many problems with such designs. Evaluations of open-space designs for office automation should be performed.

- Technological advancements have permitted the automation of many building systems; operational, service, environmental, etc. However, the ability to automate systems does not mean that they should be automated. Studies have shown that individuals desire to have more, not less control of their workspaces and environments. Better information is required in making decisions of this type.

- The primary,justification for automation is increased productivity, yet the methods avallable for making productivity measurements are quite primitive and need improvement. It is of particular importance in the present study to determine the relationship of design issues to productivity.

- The integration of operational office systems with other building systems is a major design challenge today. The experiences of the design community and office automation users in federal and private sector office buildings in sýstem integration ought to be evaluated.

- The architectural programming process should be improved to respond in a timely way to the rapid technological changes in office automation systems. Procedures are needed to develop new information and evaluate proposed solutions which minimize the disruption of ongoing activities. One approach developed for the state-of-the-art report appears in table 1 . 
Table 1. Analtylc Approach for Relating Technology Issues to Design (Rubin and Murray)

INFORMATION/MANAGEMENT SYSTEMS

Record Storage \& Management

Internal ma11 generation

\& Distribution

Document distribution

Document preparation

Organization of activities

Specialized and

decentral1zed

Space set aside

Minimal necessary graphics.
Limited paper,

Electronic files

Electronic

Opt1cal Character

Recognition devices (Hard copy readied for electronfc distribution)

Centrallzed and electronic Manual typing, artwork,

Work stations - clerical, managerial, professional

More power, wiring to accomodate future needs

Detalled planning of systems essential, bullding, mgmt, communication, info.
- Less space for file cabinets, changed layout

- Added electronics, added coollng load

- Smaller mall room, more electronics

- Need for physical separation of system (Noisy), special acoustic design

- Large work station for preparing documents, less space needs for visual arts

- Change in adjacency locations e.g., management-secretarial

- More electronics and capability to access information from various sources (wiring, cooling)

- Added capacity for electronics power; plan for "local" cooling

- Much greater need for detalled architectural programing activity

POWER SYSTEMS

Emergency Power

Wire Distribution

Techniques
None

Conduits

Under floor systems

In-wall outlets
Batteries, Generator -

Support for electrical equipment during outage

Flat wre cables under carpet

Ralsed floors
- Additional space, special venting systems, fuel storage, special flooring for acid, fuel runoff; fire protection, security

- New floor systems - carpets

- Increased size of floor/celling systems

- Changed power lcading factorsless load per local circuit, more runs

- Changed needs for wire closet space

- Special protection for cables

\section{OFFICE TECHNOLOGY}

BASED ACTIVITIES

\section{Typing}

\section{Communication-} individual

Filing

Facsimile

production

Hands-on duplicating

Paper copy
WP system

Electronic mall

Centralized data base

Duplication at a distance - FAX machine

CRT's, microfiche
Glare free lighting, additional workspace

CRT terminal, wlring

Specialized computer facility ralsed floor, clean, emergency power, less paper storage space

Specialized facility to accomodate a variety of devices, acoustic treatment, cooling

Special lighting, additional desktop area for more equipment 


\subsection{WHAT HAPPENS NEXT?}

An Interim design guldeline document will be prepared for use by the General Services Administration and the architectural, design and building communities which serve them. The guideline will contain a compllation of design practices, considerations and implications of office automation systems. The document will be prepared from information derived from the following sources:

- The findings contalned in the state-of-the-art report (NBSIR 83-2784-1).

- A Roundtable Conference, comprised of design and office automation experts and representatives from GSA and NBS. Focused discussions will be held to obtain a consensus of design guidelines for the automated office.

- Interviews will be conducted with subject area experts to fill in informational gaps. 


\section{BIBLIOGRAPHY}

1. "White Collar Productivity: The National Challenge," The Productivity Center, Houston, Texas, 1983.

2. Zuboff, S., "Psychological and Organizational Implications of ComputerMediated Work," CISR \#71, Cambridge, Mass., June 1981 .

3. Uhlig, R., Faber, D., and Bair, J., The Office of the Future, North Holland Pub. Co., New York, N.Y. 1979.

4. Yates, R., "Human Factors Aspects of the Electronic office "In The Electronic Office, IERE Conf. Proc., Proc. 非5, London, England, 1980.

5. Video Display, Work and Vision, National Academy Press, Washington, D.C., 1980 .

6. Marans, R. and Spreckelmeyer, K., "Evaluating Open and Conventional office Design," Environment and Behavior, Vol. 14, No. 3, May 1982. 
NBS.114A (REV. 2-8C)

\begin{tabular}{c|c} 
U.S. DEPT. OF COMM. & 1. PUBLICATION OR \\
BIBLIOGRAPHIC DATA & REPORT NO. \\
SHEET (See instructions) & $83-2784-2$
\end{tabular}

2. Performlng Organ. Report Nof 3. Publication Date

SHEET (See instructions)

REPORT NO.

December 1983

4. TITLE AND SUBTITLE

The Automated office: An Environment for Productive Work, or an Information Factory?: Executive Summary

5. $\operatorname{AUTHOR}(S)$

Arthur I. Rubin

6. PERFORMING ORGANIZATION (If joint or other than NBS, see instructions)

7. Contract/Grant No.

NATIONAL BUREAU OF STANDARDS

DEPARTMENT OF COMMERCE

8. Type of Report \& Perlod Covered

WASHINGTON, D.C. 20234

9. SPONSORING ORGANIZATION NAME AND CCMPLETE ADDRESS (Street. City, Stote, ZIP)

Genera1 Services Administration

Washington, D.C. 20405

10. SUPPLEMENTARY NOTES

Document describes a computer program; SF-185, FIPS Software Summary, is attached.

11. ABSTRACT (A 200-word or less factual summary of most significant information. If document includes a significant bibliogrophy or literoture survey. mention it here)

This study is a report of research findings and recommendations covering topics which influence automated office design. The subjects covered are: office design, office information systems, organizational factors, ergonomics, technology and communications. Advances in technology, coupled with the explosive growth of office-based work have resulted in the automation of many offices. To date, technology has provided the major impetus for automation, with mixed results. Systems frequently do not meet the needs of the end-user because of the lack of appropriate planning. Design issues are particularly neglected during planning, resulting in problems with the visual, thermal, and acoustic environment in many offices. These effects are particularly detrimental since many office automation, management, and design experts agree that the quality of the environment is especially important in the electronic office - to offset the impersonality of many office tasks, and changes in work procedures resulting in limited social interaction with colleagues. These issues are discussed as they relate to the development of design guidelines and criteria for automated offices. The report contains an extensive bibliography, dealing with the topics cited above.

12. KEY WORDS (Six to twelve entries; alphabetical order; capitalize only proper names; and separate key words by semicolons) Acoustic privacy; design criteria; ergonomics; lighting; office automation; office design criteria; quality-of-Iife; space planning; thermal comfort; VDT s (video display terminal); work station.

\section{AVAILABILITY}

X Unlimited

For Official Distribution. Do Not Release to NTIS

Order From Superintendent of Documents, U.S. Government Printing Office, Washington, D.C. 20402.

Order From National Technical Information Service (NTIS), Springfield, VA. 2216I
14. NO. OF

PRINTED PAGES

$$
20
$$

15. Price

$\$ 7.00$ 

$x=$ 